\title{
PROPERTIES OF MICROALGAE OIL FROM THE SPECIES Chlorella protothecoides AND ITS ETHYLIC BIODIESEL
}

\author{
F. R. M. Batista ${ }^{1 *}$, K. W. Lucchesi ${ }^{2}$, N. D. D. Carareto ${ }^{1}$, \\ M. C. D. Costa $^{1}$ and A. J. A. Meirelles ${ }^{1}$ \\ ${ }^{1}$ ExTrAE, Laboratory of Extraction, Applied Thermodynamics and Equilibrium, Department of Food Engineering, Faculty of Food \\ Engineering, P.O. Box 6121, University of Campinas-UNICAMP, 13083-862, Campinas, SP, Brazil. \\ E-mail: fbatista@usp.br,karol.wl@gmail.com,tomze@fea.unicamp.br. \\ ${ }^{2}$ School of Engineering of Lorena, Department of Chemical Engineering, University of São Paulo - USP, 12602-810, Lorena, SP, Brazil.
}

(Submitted: April 8, 2017 ; Revised: July 13, 2017 ; Accepted: January 3, 2018)

\begin{abstract}
Microalgae oil of the species Chlorella protothecoides was obtained via a donation of the Soley Biotechnology Institute (SOLEYBIO) and characterized according to the fatty acid profile. Ethylic biodiesel was prepared using methods adapted by the research group. Analysis of acidity, water content, and density and viscosity temperature dependence ( $293.15 \mathrm{~K}$ to $368.15 \mathrm{~K}$ ) were performed for the oil and ethylic biodiesel. The biofuel was characterized in terms of its flash and cloud points, heat capacity and cetane number. The properties studied were compared with conventional vegetable oils and biodiesel, presenting little differences and demonstrating the high viability of biodiesel from microalgae oil.

Keywords: Microalgae; Density; Viscosity; Properties; Biodiesel; Vegetable oil.
\end{abstract}

\section{INTRODUCTION}

The main sources of transportation fuels have been fossil resources. As a consequence of the decrease in reserves of this kind of fuel and increasing evidence of carbon dioxide as a main culprit for global warming, fuels from biological resources (biofuels) are being explored around the world with relative success. These biofuels can be divided into three generations: first generation, associated with biofuel produced from food sources, such as vegetable oils, starch, and sugar (Basso et al., 2013a; Batista et al., 2012; Naik et al., 2010); second generation, related with biofuel produced from cellulose derivatives, especially lignocelluloses (Naik et al., 2010); and third generation, focused specifically on microalgae, designed for fuel production as an "energy crop" (Rodgers et al, 2011).

Especially in the case of third generation biofuels, the biodiesel produced from microalgae oil has been gaining a large interest in the academic and industrial world, mainly due to the high capacity of some species to store lipids in their cells, the possibility of no competition with food, the high productivity of biomass per hectare of cultivation (around 90\% higher than palm) and the high absorption of $\mathrm{CO}_{2}$ (Demirbas and Demirbas , 2011; Moazami et al., 2011; Packer, 2009).

Some species have an average lipid content (dry basis) between $6 \%$ to $78 \%$ (Mallick et al., 2016; Karpagam et al., 2015), indicating a great potential of these microorganisms for biodiesel production. Furthermore, the high amount of valuable products that can be extracted from microalgae, such as carbohydrates (polysaccharides), proteins, polyunsaturated fatty acids and pigments (GilbertLópez et al., 2017; Lupatini et al., 2017; EsquivelHernández et al., 2017), gives microalgae a great potential for the insertion of this raw material in

\footnotetext{
*Corresponding author: fbatista@usp.br
} 
biorefineries where different products, with an ample range of economic values, can be extracted from its biomass.

Among the main biofuel that can be produced from microalgae, biodiesel has been evaluated as one of the most economically viable (Chisti, 2008; Chisti, 2010). Biodiesel is produced via the transesterification reaction. In this reaction, triacylglycerols (TAG) are converted into fatty acid alkyl esters (called "biodiesel") in the presence of a short chain alcohol and a catalyst, generating glycerol as by-product (Brunschwing et al., 2012).

Transesterification is a sequence of three reversible reactions in which TAG are broken down into diacylglycerols (DAG) and monoacylglycerols (MAG), forming esters (biodiesel) and glycerol. The reversible nature of the reactions requires the use of an excess of alcohol, ensuring the displacement of the equilibrium towards the formation of the products (biodiesel).

On an industrial scale, biodiesel is primarily synthesized using methanol due to its high reactivity. Considering that methanol is usually provided from fossil resources, the resulting biodiesel carbon emissions are therefore not $100 \%$ of vegetable origin (Brunschwing et al., 2012; Kiss et al., 2010). In this scenario, ethanol has gained great prominence as an alternative alcohol source.

Bioethanol is a very promising reactant for biodiesel production, when compared to methanol: it is not toxic and is a "green" reactant. Indeed, bioethanol production through the fermentation of biomass, a locally available and renewable raw material, makes bioethanol a more sustainable reactant than methanol, which is nowadays industrially produced from fossil fuels (Brunschwing et al., 2012). This advantage is potentiated in case of countries like Brazil, where bioethanol is produced from sugar cane.

The main disadvantages of bioethanol as reagent in the transesterification reaction are related to its low reactivity with TAGs and the presence of an azeotropic point with water (around 95/5\%wt ethanol/water). This last disadvantage jeopardizes the purification process, which usually involves successive washings with water and requires a specific dehydration step for recovering the excess ethanol in the anhydrous form (Rocha et al., 2014; Kulkarni et al., 2007).

Another important question about biodiesel production is related to the TAGs sources. In the main routes, biodiesel is produced by transesterification of edible vegetables oils (soy, palm, sunflower, rapeseed, etc.). However, other sources, such as non-edible vegetables oils, waste oils, animal fats, or microalgae oil, have aroused the interest of researchers, mainly due to non-competitiveness with food production (Singh et al., 2011; Vyas et al., 2010). Among these new sources of biodiesel production, microalgae oils are considered the main alternative raw materials.

These microorganisms can grow quickly in fresh or salt water without using arable land and not competing with food production, and many of the species provide high biomass generation and large capacity for oil production (Chen et al., 2012). Likewise, the yield of biomass per hectare of microalgae cultivation excels in productivity, up to $94 \%$ of palm oilseed with a higher yield per hectare (Demirbas and Demirbas, 2011; Moazami et al., 2011).

Taking into account the high potential of microalgae to produce lipids and other bioproducts, this paper aims to investigate some physical and thermophysical properties of microalgae oil and its ethylic biodiesel obtained from the specie Chlorella protothecoides.

\section{METHODOLOGY}

\section{Characterization of Microalgae Oil}

Chlorella is a green microorganism that can grow in autotrophic and heterotrophic conditions. In general, as vegetables, they tend to produce carbohydrates as energy source but, under some conditions, the lipid production can be increased (Kumar and Sharma, 2016).

As discussed in the scientific literature, a great amount of Chlorella species have potential for oil production, with a lipid accumulation in the range of $2 \%$ until $63 \%$ on a dry basis. Among these species, Chlorella protothecoides is an important feedstock for biodiesel production due to its high lipid content (14.6 $-57.8 \%$ on a dry basis) (Mata et al., 2010).

Samples of Chlorella protothecoides oil were obtained through a donation from SOLEY BIOTECHNOLOGY INSTITUTE (SOLEYBIO), Turkey. The microalgae were genetically modified to produce high amounts of lipids and the cultivation was performed in a Pyramid Photobioreactor System, especially developed by this Institute. According to SOLEYBIO, based on 100 tons of aqueous medium, Pyramid Photobioreactor Systems exhibit the best efficiency, and provide impressive advantages over other systems in terms of productivity (45\% higher than tubular photobioreactors), area required $(76 \%$ less than open pond), energy efficiency, and other factors studied (Kizililsoley \& Helvacioglu, 2008).

Microalgae harvest filters were used to collect microalgae biomass. After collecting microalgal sludge from aqueous media, the collected biomass was treated for 4 hours by extractive bacteria which can crack microalgae cell walls. In sequence, the biomass was processed as the following: 2 hours of ultrasonic extraction, 2 hours of microwave extraction, and 2 
hours of water extraction. After that, the biomass was cold pressed to totally separate the biomass from the oil-water mixture. Finally, the oil was separated from water and the oil phase submitted to a filtration and UV sterilization to clean the final product (microalgae oil) (Kizililsoley \& Helvacioglu, 2008). Since the extraction process is an industrial secret, the list of chemicals used in the oil extraction process was not specified.

The oil was filtered and evaporated in order to remove possible impurities and residues of solvent of the oil extraction. Its characterization was based on the esterification of TAGs using methanol as alcohol reagent. The characterization of the methylic esters (supernatant - top phase) was performed by AOCS 1-62 official method, using an Agilent 68650 capillary gas chromatograph (CGC) with a capillary column DB - 23 Agilent (50\% cyanopropyl - methylpolysiloxane), $60 \mathrm{~m}$ of length, inner diameter of $0.25 \mathrm{~mm}$ and 0.25 $\mu \mathrm{m}$ in the film.

The analyses were performed in triplicate under the following conditions: flux of $1 \mathrm{~mL} / \mathrm{min}$, linear velocity $24 \mathrm{~cm} / \mathrm{s}$, injector temperature of 523.15 $\mathrm{K}$ and temperature ramp of $383.15 \mathrm{~K}$ for $5 \mathrm{~min}$, $383.15 \mathrm{~K}-488.15 \mathrm{~K}(5 \mathrm{~K} / \mathrm{min}), 488.15 \mathrm{~K}-25 \mathrm{~min}$. The carrier gas used was helium and samples with injection volume of $1 \mathrm{~mL}$. The esters were identified by comparison with the retention times of the injected standards and quantification was performed by internal standardization. With this methodology it was possible to quantify the microalgae oil in terms of fatty acids. From this fatty acid composition the TAG composition was estimated following the methodology proposed by Antoniosi-Filho et al. (1995). With the TAG composition, the oil molar mass was calculated.

Uncertainties in the fatty acid composition of microalgae oil were evaluated through standard deviations, taking into account the average of three replicates and following Eq. 1 below, where $S D$ is the standard deviation, $N$ is the number of replicates, $x_{i}$ is the mole fraction of the fatty acid in replicates $i$ and $\bar{x}$ is the average of fatty acid mole fractions.

$$
S D=\sqrt{\frac{1}{N-1} \sum_{i=1}^{N}\left(x_{i}-\bar{x}\right)^{2}}
$$

\section{Ethylic Biodiesel Production}

Ethylic biodiesel was produced using absolute ethanol (Merck PA, $>=99.9 \%$ ) as alcohol reagent, homogeneous catalysis with sodium ethoxide $(1 \%$ of oil mass) and molar ratio ethanol/oil of 9/1. The reaction temperature was maintained at $333.15 \mathrm{~K}$ with stirring $(150 \mathrm{rpm})$ for approximately 1.5 hours. The reaction products were kept at rest for 24 hours in a separatory funnel to complete phase separation. After this period the glycerol rich phase (heavy phase) was discarded, and the light phase (biodiesel/ethanol rich phase) was subjected to repeated washings with hot water to separate the ethanol and catalyst residues from biodiesel. The purified biodiesel was then dried in a kiln at $388.15 \mathrm{~K}$ for 3 hours. Finally, the dry biodiesel was filtered through Amberlite BD10 resin. This resin has the aim of removing the excess alcohol as well as water, partial glycerides and other impurities. In comparison to traditional methodologies of biodiesel production the present purification step represents an important difference.

\section{Acidity Analyses}

Acidity of microalgae oil and its ethylic biodiesel were evaluated through cold titration with sodium hydroxide $(\mathrm{NaOH})$ according to the IUPAC method 2.201. The titration was performed in an automatic titrator (Metrohm - Model 808 Titrando) coupled with TIAMO software and the analyses were performed in triplicate for each sample. The uncertainties were evaluated by standard deviations following Eq. 1.

\section{Water Content Analyses}

Determination of water content in oil and ethylic biodiesel were performed using the coulometric Karl Fischer equipment (Metrohm - Model 831 KF Coulometer) coupled with TIAMO, according to the official method $\mathrm{Ca}$ 2e-84. The uncertainties were calculated using Eq. 1.

\section{Density and Viscosity}

Densities and viscosities of microalgae oil and ethylic biodiesel were measured using the densimeter Anton Paar DMA 4500 integrated with the capillary viscometer Anton Paar AMVn. Temperature was varied within the range 293.15 to $358.15 \mathrm{~K}$ with increments of $5 \mathrm{~K}$.

The density data was correlated using Eq. 2, shown below, where $\rho$ is density $\left(\mathrm{g} . \mathrm{cm}^{-3}\right)$ and $T$ corresponds to temperature in $\mathrm{K}$.

$$
\rho=A \cdot T+B
$$

The method developed by Halvorsen et al. (1993) was used for predicting the microalgae oil density and the Halvorsen-Constantinou-Constantinou (HCC) methodology was tested, with the same objective, in the case of microalgae oil biodiesel (Basso et al., 2013b). The constants required in the Halvorsen method, such as critical properties (temperature and pressure) and Rackett's parameter were taken directly from the original paper (Halvorsen et al., 1993) 
for the microalgae oil. For the microalgae ethylic biodiesel the critical properties were calculated using the methodology proposed by Constantinou and Gani (1994) and the Rackett's parameter were taken from Basso et al. (2013b).

The dynamic viscosities of microalgae oil and biodiesel were correlated using Eq.3 and Eq.4, where $\mu$ is the dynamic viscosity in $\mathrm{mPa} . \mathrm{S}$ and $T$ the temperature in $\mathrm{K}$. In both equations three specific parameters are present (A, B and C) and the accuracy of these models was studied.

$\ln \mu=A+\frac{B}{T+C}$

$\ln \mu=A+\frac{B}{T}+\frac{C}{T^{2}}$

The methodology suggested by Ceriani et al. (2007) was also used for predicting the viscosity of microalgae ethylic biodiesel. In this case the viscosities of each ethyl ester were predicted according to the mentioned methodology and the biodiesel viscosities were calculated using Eq. 5 below:

$$
\ln (\mu)=\sum_{i} \ln \left(\mu_{i}\right) \cdot x_{i}
$$

where $\mu_{i}$ and $x_{i}$ are the dynamic viscosities (mPa.s) and mole fractions of each ethyl ester in the biodiesel composition, respectively. The ethylic biodiesel composition was obtained on the basis of the oil compositions in terms of fatty acids given in Table 1.

Rodenbush et al. (1999) suggested a correlation between density $\left(\rho / \mathrm{g} . \mathrm{cm}^{3}\right)$ and viscosity $\left(\eta / \mathrm{mm}^{2} . \mathrm{s}^{-1}\right)$ according to Eq. 6 below. Note that the viscosity in Eq. 6 is the kinematic viscosity. This approach was also tested for microalgae oil and biodiesel.

$$
\rho=D+\frac{E}{\eta^{1 / 2}}
$$

The deviations between experimental and predicted (or calculated) values for densities and viscosities of microalgae oil and its ethylic biodiesel were evaluated following Eq. 7 and Eq. 8 below, where $\xi$ stands for density or viscosity and $n$ for the number of experimental points.

$$
A D(\%)=100 \cdot\left[\frac{a b s\left(\xi^{e x p}-\xi^{c a l c}\right)}{\xi^{\exp }}\right]
$$

$A R D(\%)=\frac{\sum A D}{n}$

Densities and viscosities of microalgae oil and its ethylic biodiesel were also compared with other common vegetable oils and ethylic biodiesels.

Statistical analyses of the parameters of equations 2, 3, 4 and 6 where performed via ANOVA, according to the software Origin 8.0 by OriginLab ${ }^{\circledR}$. The confidence interval considered was $95 \%$ and the standard deviation for each parameter was evaluated. The residuals (difference between experimental and fitted values) were calculated together with the determination coefficient $\left(\mathrm{R}^{2}\right)$, aiming to make inferences about the fitting quality.

The accuracy of the equations mentioned above for calculating viscosities and densities were further checked through the calculation of the determination coefficients between experimental and predicted values.

\section{Microalgae Ethylic Biodiesel Flash Point}

The flash point (FP) is the lowest temperature at which the biodiesel can vaporize to form an ignitable mixture with air. Flash point is often used as a descriptive characteristic of liquid fuels, and it is also used to characterize the fire hazard associated with volatile liquids.

Table 1. Microalgae oil composition (mass \%).

\begin{tabular}{ccccc}
\hline Faty Acids & Soybean $^{a}$ & Palm $^{\boldsymbol{a}}$ & Sunflower $^{\boldsymbol{a}}$ & Microalgae $^{\mathbf{b}}$ \\
\hline C $12: 0$ & - & $0.10 \%$ & - & - \\
C $14: 0$ & - & $0.90 \%$ & - & - \\
C $16: 0$ & $11.20 \%$ & $45.60 \%$ & $6.70 \%$ & $(4.79 \pm 0.02) \%$ \\
C $16: 1$ & $0.20 \%$ & $0.40 \%$ & $0.30 \%$ & $(0.23 \pm 0.01) \%$ \\
C $18: 0$ & $2.90 \%$ & $3.80 \%$ & $2.90 \%$ & $(1.72 \pm 0.01) \%$ \\
C $18: 1$ & $25.20 \%$ & $10.50 \%$ & $38.70 \%$ & $(62.17 \pm 0.18) \%$ \\
C $18: 2$ & $55.40 \%$ & $0.10 \%$ & $51.30 \%$ & $(22.33 \pm 0.10) \%$ \\
C $18: 3$ & $5.00 \%$ & - & - & $(6.66 \pm 0.08) \%$ \\
C $20: 0$ & - & - & - & $(0.55 \pm 0.01) \%$ \\
C $20: 1$ & $0.10 \%$ & $0.10 \%$ & $0.10 \%$ & $(1.55 \pm 0.02) \%$ \\
Other & - & $50.40 \%$ & $9.60 \%$ & - \\
Saturated & $14.10 \%$ & $49.60 \%$ & $90.30 \%$ & $(7.06 \pm 0.01) \%$ \\
Unsaturated & $85.90 \%$ & & & $(92.94 \pm 0.02) \%$ \\
\hline
\end{tabular}

${ }^{\mathrm{a}}$ Esteban et al. (2012), ${ }^{\mathrm{b}} \mathrm{x} \pm \mathrm{SD}$, where SD is standard deviation. 
This property was experimentally determined using a Miniflash FLPH (Grabner Instruments, Austria). The measurements were made in quintuplicate, following the official method ASTM D6450 and using a sample volume of $1 \mathrm{~mL}$ in a temperature range of $438.15 \mathrm{~K}$ $476.15 \mathrm{~K}$. The uncertainties of the measurements were calculated according to Eq. 1.

\section{Microalgae Ethylic Biodiesel Cold Flow Properties and Heat Capacity}

Biodiesel cold flow properties are important since the presence of crystals in the liquid solution can clog fuel lines and filters, causing the collapse of the combustion system.

Two important cold properties of biodiesel are widely reported in the scientific literature: Cloud Point (CP) and Pour Point (PP). CP is the temperature at which a liquid mixture becomes cloudy due to the formation of the first crystals. At this temperature, the liquid does not lose its flow capacity, but if the temperature continues to decrease the crystals grow quickly until the material reaches its pour point (PP), defined as the lowest temperature at which the liquid still flows. At the PP, the liquid becomes semisolid and, due to the loss of flow characteristics, the combustion system tends to collapse (Refaat, 2009).

The melting point (MP) represents the temperature at which a solid sample melts completely. Another important thermal property related to the processes of heat transfer to or from a liquid fuel is its specific heat capacity $\left(\mathrm{C}_{\mathrm{p}}\right)$. In the present work, differential scanning calorimetry (DSC) was used to measure the $\mathrm{CP}, \mathrm{MP}$ and PP temperatures and to determine the specific heat capacity as a function of temperature. For this purpose, a Perkin Elmer DSC (model 8500) equipped with a cooling system (Intracooler II) was used. Samples of biodiesel (2 to $5 \mathrm{mg}$ ) were weighed in a microanalytical balance (Perkin Elmer AD6) with $0.005 \mathrm{mg}$ of accuracy and put in sealed aluminum pans. An empty pan was used as reference.

DSC temperature and heat flow calibrations were performed using indium (purity of 99.99\%) certified by Perkin Elmer $\odot$, n-decane (purity of $99.9 \%$ ) and naphthalene (purity of 99.9\%), both purchased from Sigma-Aldrich. High purity nitrogen supplied by Air Liquide (purity of $99.999 \%$ ) was used as purge gas.

Melting and Crystallization Behavior - For the cooling curve, the samples were kept isothermal at $293.15 \mathrm{~K}$ during $3 \mathrm{~min}$, then cooled to $188.15 \mathrm{~K}$ using a cooling rate of $2 \mathrm{~K} \cdot \mathrm{min}^{-1}$, and kept isothermal during $30 \mathrm{~min}$ at this temperature. In the same way, for the melting curve the samples were heated from 188.15 $\mathrm{K}$ to $293.15 \mathrm{~K}$ using a heating rate of $2 \mathrm{~K} \cdot \mathrm{min}^{-1}$. Since the biodiesel is a multicomponent system and the thermal curve generated by the DSC analysis tends to present overlapped peaks, the peak top temperatures, calculated by the Perkin Elmer DSC software (Pyris $\mathrm{C}$ ), were used to represent MP, CP and PP. As previously reported, peak top temperatures have more accuracy in the DSC thermal response than onset temperatures (Carareto et al., 2011; Costa et al., 2007). The temperature uncertainty for the DSC methods was estimated to be $0.3 \mathrm{~K}$.

Specific Heat capacity (Cp) - The $C p$ of microalgae ethylic biodiesel was measured using a Stepscan DSC method through the following set of parameters: linear heating rate of $2 \mathrm{~K} \cdot \mathrm{min}^{-1}$, second temperature of 0.5 $\mathrm{K}$, isothermal step of $2 \mathrm{~min}$ and stability criterion of $0.005 \mathrm{~mW}$. The analyses were made in triplicate with an accuracy of $0.03 \mathrm{~J} \cdot(\mathrm{g} \cdot \mathrm{K})^{-1}$. $C p$ of a sample can be calculated directly from the results of a Stepscan DSC analysis using the Pyris $\mathbb{C}$ software from Perkin Elmer.

\section{Microalgae Ethylic Biodiesel Cetane Number (CN)}

$C N$ is an important characteristic of diesel related with the pollutant gas emission. In accordance with ASTM D613, $C N$ reflects the diesel ignition delay time. Higher $C N$ values indicates a short time between the ignition and the entry of a fuel into the combustion chamber, a feature that corresponds to a lower emission of pollutant gases, such as nitrogen oxides $\left(\mathrm{NO}_{\mathrm{x}}\right)$, and a lower amount of unburned hydrocarbons, increasing the combustion efficiency (Tong et al., 2011).

In the present work the $\mathrm{CN}$ of microalgae ethylic biodiesel was estimated following the methodology proposed by Tong et al. (2011). According to this methodology, the $C N$ of biodiesel is estimated based on the $C N$ of each pure fatty acid ethyl ester (FAEE), following Eq. 9, where $C N$ is the cetane number of biodiesel, $C N_{i}$ is the cetane number of each pure FAEE and $w_{i}$ is the mass percentage of each FAEE.

$C N=1.068 \cdot \sum\left(C N_{i} \cdot w_{i}\right)-6.747$

The $C N$ of each fatty ester was estimated using the equations developed by Tong et al. (2011) that differentiate the fatty compounds into saturated, mono-unsaturated and poly-unsaturated and express the $C N$ as a function of the number of carbon atoms in the fatty acid moiety, the total number of carbon atoms in the ester molecule and the number of double bonds in the fatty acid moiety.

\section{RESULTS AND DISCUSSION}

\section{Characterization of Microalgae Oil}

Following the methodology previously explained, microalgae oil was characterized according to fatty 
acid composition and the results are presented in Table 1 , comparing it with three other common vegetable oils.

Microalgae oil has the highest content of oleic acid (C18:1) compared to other common vegetable oils. This fact gives the microalgae oil a very important nutritional application (source of omega-9, important in the synthesis of hormones), as well as applications in the cosmetic and medical industries.

In relation to content of unsaturated fatty acids, microalgae oil shows significant differences only regarding palm oil, presenting a slightly higher content when compared with soybean and sunflower oils.

Taking into account the fatty acid composition and the methodology proposed by Antoniosi-Filho et al. (1995), Table 2 shows the estimated TAGs composition for the microalgae oil.

It is clear from Table 2 that the TAGs OOO, OOL and OOP represent more than $55 \%$ of the whole composition of microalgae oil. This result was expected due to the fact that oleic acid contributes more than $60 \%$ of the entire microalgae oil fatty acid composition (see Table 1). In comparison with soybean and palm oil, the three major TAGs in microalgae oil represent a contribution of only $16.1 \%$ (soybean oil) and $29.7 \%$ (palm oil). With the TAGs composition, the molar mass of microalgae oil was evaluated as 880.46 g. $\mathrm{mol}^{-1}$.

The distribution of fatty acids determined in this present work can undergo modifications depending on the method of oil extraction and the process of microorganism cultivation. Especially in the case of

Table 2. TAG composition of microalgae oil (\% molar in relation to total TAG).

\begin{tabular}{|c|c|c|c|c|c|}
\hline TAG $^{1}$ & Chain & $\mathbf{M M}^{2}$ & Soybean $^{3}$ & Palm $^{3}$ & Microalgae \\
\hline PPP & $51: 0$ & 807.32 & - & 5.6 & - \\
\hline PLP & $50: 2$ & 831.35 & 2.20 & 10.30 & 0.15 \\
\hline POP & $50: 1$ & 833.37 & 1.90 & 31.30 & 0.42 \\
\hline PLLn & $52: 5$ & 853.36 & 3.50 & - & 0.50 \\
\hline LLP & $52: 4$ & 855.38 & 14.60 & 2.10 & 2.42 \\
\hline PLO & $52: 3$ & 857.39 & 11.40 & 10.30 & 4.87 \\
\hline OOP & $52: 2$ & 859.41 & 5.50 & 23.90 & 6.34 \\
\hline POS & $52: 1$ & 861.42 & 1.10 & 5.60 & 0.27 \\
\hline LnLnL & $54: 8$ & 875.37 & 1.30 & - & 0.31 \\
\hline LLLn & $54: 7$ & 877.38 & 8.00 & - & 1.87 \\
\hline LLL & $54: 6$ & 879.40 & 22.2 & - & 6.77 \\
\hline LLO & $54: 5$ & 881.41 & 16.40 & 1.00 & 17.34 \\
\hline OOL & $54: 4$ & 883.43 & 8.10 & 1.80 & 26.66 \\
\hline $\mathrm{OOO}$ & $54: 3$ & 885.44 & 2.50 & 4.00 & 25.48 \\
\hline OOS & $54: 2$ & 887.46 & 1.30 & 2.70 & 2.34 \\
\hline LLnGa & $56: 6$ & 907.45 & - & - & 0.13 \\
\hline GaOLn & $56: 5$ & 909.47 & - & - & 0.49 \\
\hline $\mathrm{GaOL}$ & $56: 4$ & 911.48 & - & - & 1.31 \\
\hline OOGa & $56: 3$ & 913.50 & - & - & 1.63 \\
\hline OOA & $56: 2$ & 915.51 & - & - & 0.69 \\
\hline Other & - & - & - & 1.40 & - \\
\hline
\end{tabular}

microalgae cultivation, genetic modifications can increase substantially the amount of lipids produced and influence the fatty acid distribution.

Taking into account that a high amount of lipids in microalgae biomass is essential to make biodiesel production feasible, the search for alternative techniques to increase the lipid content of microalgae is necessary. In this sense, Li et al. (2015) presented a structured heterotrophic-iron (II) induction strategy for lipid accumulation in microalgae of the species Chlorella protothecoides. The authors showed that with this technique, microalgae cultured in heterotrophic medium in the presence of iron (II) were able to accumulate up to $62 \%$ of lipid on a dry basis, with a maximum productivity of $820.17 \mathrm{mg} /$ day, representing an increase of 3.21 times in the productivity, when compared with the conventional heterotrophic cultivation. The main advantage of this method is that it does not require a genetic modification in the microorganism to increase the lipid content, which, theoretically, can minimize crop costs.

\section{Ethylic Biodiesel Production}

After the characterization of microalgae oil, the ethylic biodiesel was produced following the methodology previously explained. The biofuel presented a slightly greenish color, probably due to the high content of chlorophyll in the oil.

\section{Acidity Analyses}

Acidity analyses for microalgae oil were performed in quadruplicate, presenting a value of $0.193 \mathrm{mg}$ $\mathrm{KOH} / \mathrm{g}$ of oil, with a standard deviation of $0.006 \mathrm{mg}$ $\mathrm{KOH} / \mathrm{g}$ of oil $(0.193 \pm 0.006)$. This result indicates low oil acidity, enabling the production of ethylic biodiesel through the use of a basic catalyst, since the problems related to soap formation during the transesterification reaction will be minimized, making the biodiesel purification steps easier.

The same analyses were performed for the ethylic biodiesel that presented an acidity of $0.224 \mathrm{mg} \mathrm{KOH} / \mathrm{g}$ of biodiesel, with a standard deviation of $0.006 \mathrm{mg}$ $\mathrm{KOH} / \mathrm{g}$ of biodiesel $(0.224 \pm 0.006)$. According to the norms established by Brazilian, European and American legislations, the maximum acidity allowed for biodiesel is $0.5 \mathrm{mg} \mathrm{KOH} / \mathrm{g}$ of biodiesel (Lôbo et al., 2009), indicating that the microalgae ethylic biodiesel produced meets the required standard, validating the production methodology.

\section{Water Content Analyses}

Water content analyses of microalgae oil and its ethylic biodiesel were performed with 14 replicates. 
An average value of $857.92 \mathrm{ppm}$, or 0.086 mass\%, with a standard deviation of $0.005 \%$, was found for the oil $(0.086 \% \pm 0.005 \%)$. This amount of moisture is lower than the values found for common vegetable oils, such as: palm oil $-0.22 \%$ (Melero et al., 2000), soybean oil $-0.32 \%$ (Silva et al., 2010) and sunflower oil $-0.18 \%$ (Alonso et al., 2005). The low moisture content potentiates the transesterification reaction and provides an additional advantage of microalgae oil as an alternative non-food raw material for biodiesel production. It is important to mention that the water content of microalgae oil will depend, among other factors, on the species, biomass drying methods and of oil extraction methods.

The official standards EN ISO 12937 e ASTM D6304, both adopted in Brazil and around the world, establish that the maximum water content in the biodiesel must be $500 \mathrm{ppm}$ ( $\mathrm{mg}$ of water $/ \mathrm{kg}$ of biodiesel). The results showed an average of 183.62 ppm with standard deviation of $27.86 \mathrm{ppm}(0.018 \% \pm$ $0.003 \%$ in mass), indicating that the ethylic biodiesel produced meets the international standards.

\section{Density and Viscosity}

Biodiesel must have properties very similar to those of fossil diesel to enable direct use in combustion engines. The large size of the triglyceride molecules contained in vegetable oils results in a higher viscosity, higher density and lower volatility when compared to conventional diesel fuel, causing some problems in the engine ignition (Esteban et al., 2012). However, as pointed by Nwafor (2003), fuels with high viscosity have a greater lubricating effect, contributing to a longer life of the engine.

Therefore, the direct use of biodiesel in diesel combustion engines requires an adjustment of the physical properties, particularly regarding density and viscosity. The biofuel should have a low viscosity to allow a better atomization during combustion, improving the efficiency of its burning. This reduction is achieved through a pre-heating before burning in the cylinders (Esteban et al., 2012). Thus, the temperature influence upon viscosity and density of microalgae oil and its ethylic biodiesel is important for the feasibility of biodiesel as an alternative fuel.

Following the methodology previously explained, density and viscosity of microalgae oil and its ethylic biodiesel were studied in the temperature range of $293.15 \mathrm{~K}$ to $358.15 \mathrm{~K}$. Figure 1 shows the density and viscosity of microalgae oil, compared with some common vegetable oils, indicating that they follow the same trend of decreasing with the temperature increase. Experimental data for density and viscosity of microalgae oil are presented in Appendix A.

Figure 2 shows the density and viscosity of microalgae oil biodiesel compared with other
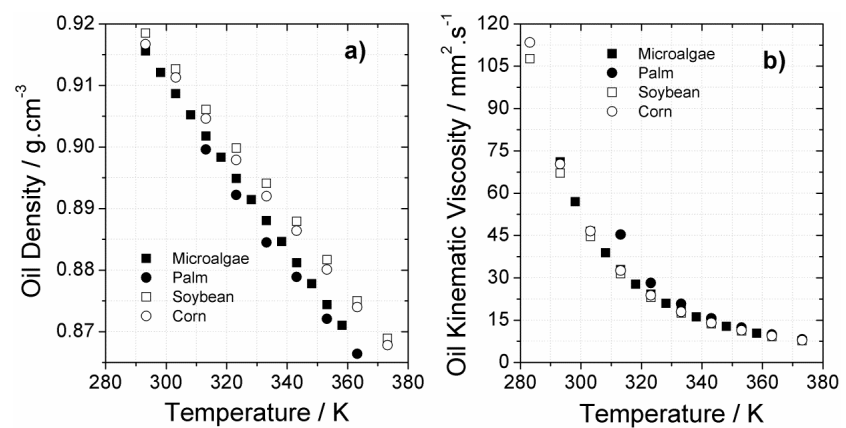

Figure 1. Density (a) and Viscosity (b) for vegetables oils (Esteban et al., 2012) and microalgae oil.
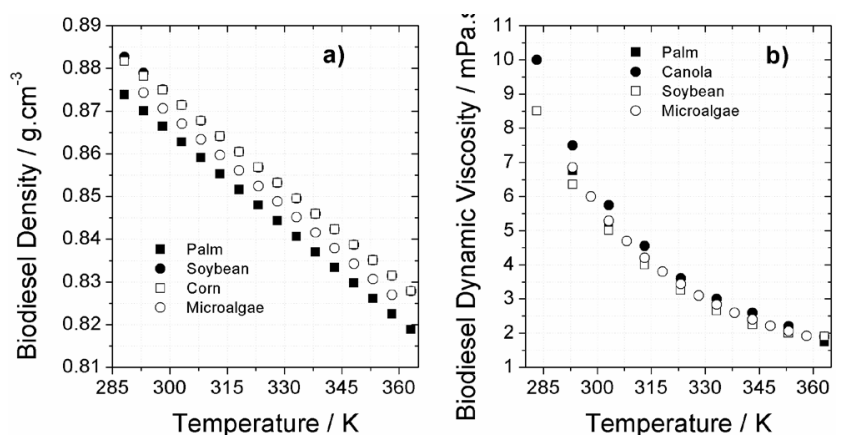

Figure 2. Density (a) and Viscosity (b) for conventional (Baroutian et al., 2008 and Basso et al., 2013b) and microalgae ethylic biodiesel.

conventional ethylic biodiesel (Basso et al., 2013b; Baroutian et al., 2008). Both properties follow trends similar to those observed for common biodiesels. Nevertheless, the density of microalgae biodiesel has values intermediate between those observed for palm and for soybean (or corn) biodiesels, a behavior related to their differences in composition. In fact, biodiesel density increases with the number of unsaturations and decreases as its average molecular mass increases (Rodenbush et al., 1999).

Reliable correlations of density and viscosity of oils and the corresponding biodiesels, as a function of temperature, may help in the optimization of existing production processes and in the development of new ones. Density and viscosity of microalgae oil and its biodiesel were correlated with temperature according to Eq. 2 (density) and Eq. 3 and 4 in the case of viscosity. The obtained parameters, standard deviations, the correlation coefficients $\left(\mathrm{R}^{2}\right)$ and the average relative deviations are given in Table 3 . The values indicate that the linear model describes correctly the density dependence on temperature and for viscosity both models have a very similar performance.

Figure 3 shows the residuals generated by the fitted models. It is clear that the residuals generated by the oil density model (Eq. 2) presented a quadratic trend. However, the low value of the ARD and the high $\mathrm{R}^{2}$ value indicate that this model can be appropriate. The other residues presented a random trend, as expected. 
Table 3. Correlation parameters for density and viscosity models (293.15 K to $358.15 \mathrm{~K}$ ).

\begin{tabular}{|c|c|c|c|c|c|c|c|c|}
\hline \multicolumn{9}{|c|}{ Density } \\
\hline & \multicolumn{3}{|c|}{ Oil } & SD $^{\mathbf{a}}$ & \multicolumn{2}{|c|}{ Biodiesel } & \multicolumn{2}{|c|}{ SD $^{\mathbf{a}}$} \\
\hline$A / \mathrm{g} \cdot \mathrm{cm}^{-3} \cdot \mathrm{K}^{-1}$ & & $-6.8580 \cdot 10^{-4}$ & & $4 \cdot 10^{-7}$ & \multicolumn{2}{|c|}{$-7.2789 \cdot 10^{-4}$} & \multicolumn{2}{|c|}{$1.6 \cdot 10^{-7}$} \\
\hline$B / \mathrm{g} \cdot \mathrm{cm}^{-3}$ & & 1.1165 & 1.1165 & $2 \cdot 10^{-4}$ & \multicolumn{2}{|c|}{1.08770} & \multicolumn{2}{|c|}{$5 \cdot 10^{-5}$} \\
\hline ARD (\%) & & 0.04 & & - & \multicolumn{2}{|c|}{0.01} & \multicolumn{2}{|c|}{ - } \\
\hline \multirow[t]{4}{*}{$\mathrm{R}^{2}$} & & 0.99999 & & - & \multicolumn{2}{|c|}{0.99999} & \multicolumn{2}{|c|}{-} \\
\hline & \multicolumn{4}{|c|}{ Viscosity } & & & & \\
\hline & \multicolumn{4}{|c|}{ Model 1 (Eq 3) } & \multicolumn{4}{|c|}{ Model 2 (Eq. 4) } \\
\hline & Oil & SD $^{\mathbf{a}}$ & Biodiesel & SD $^{\mathbf{a}}$ & Oil & SD $^{\mathbf{a}}$ & Biodiesel & SD $^{\mathbf{a}}$ \\
\hline$A / \mathrm{mPa} \cdot \mathrm{s}$ & -1.56 & 0.13 & -2.60 & 0.07 & 4.51 & 0.63 & -0.85 & 0.19 \\
\hline$B / \mathrm{mPa} \cdot \mathrm{s} \cdot \mathrm{K}$ & 718 & 38 & 748 & 27 & -4075 & 89 & -710 & 21 \\
\hline $\mathrm{C}^{\mathrm{b}}$ & -168 & 4 & -128 & 4 & $1.16 \cdot 10^{6}$ & $6 \cdot 10^{4}$ & $4.46 \cdot 10^{5}$ & $2 \cdot 10^{3}$ \\
\hline ARD (\%) & 0.49 & - & 0.16 & - & 0.66 & - & 0.15 & - \\
\hline $\mathrm{R}^{2}$ & 0.99993 & - & 0.99997 & - & 0.99987 & - & 0.99997 & - \\
\hline
\end{tabular}

Standard deviation; ${ }^{\mathrm{b}}$ unities: $\mathrm{K}$ for model 1 and $\mathrm{K}^{2}$ for model 2.
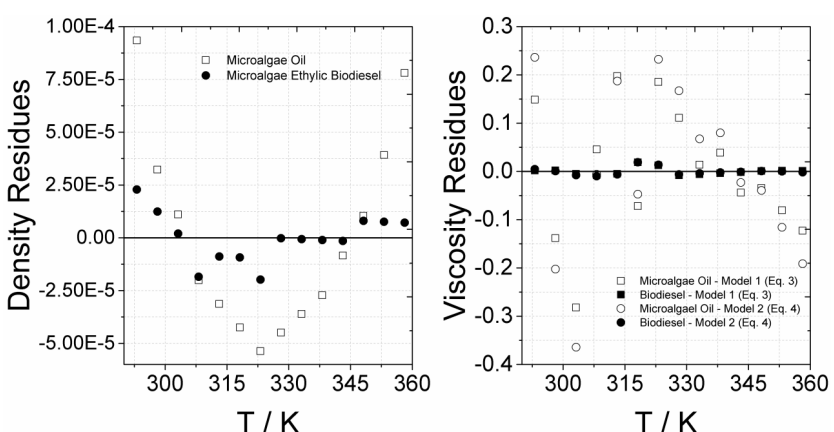

Figure 3. Density and viscosity residues.

As mentioned before, the prediction of density and viscosity (without experimental data), especially in the case of viscosity whose experimental measurements are more complicated, is fundamental to simulate a complex process such as the biodiesel production process. Thus, following the methodology previously explained, the density of microalgae oil and its ethylic biodiesel, and the viscosity of ethylic biodiesel were estimated as function of temperature.

Figure 4 shows the predicted density data as a function of the experimental values, confirming the reliability of the models used to estimate the density for microalgae oil and its ethylic biodiesel. The good

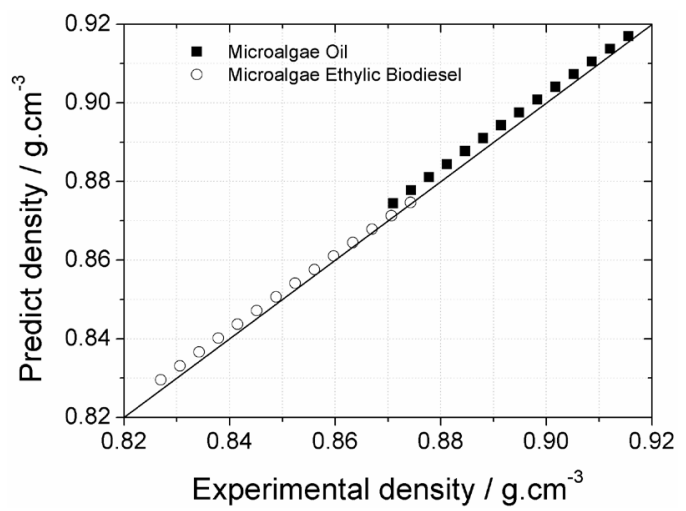

Figure 4. Correlation between experimental and predicted density for microalgae oil and its ethylic biodiesel. accuracy shown in Figure 4 confirms the low ARD found for oil $(0.29 \%)$ and biodiesel $(0.20 \%)$ densities and the high $\mathrm{R}^{2}$-values (0.9999 densities), indicating the reliability of the density model.

Figure 5 shows the experimental and estimated viscosity of microalgae ethylic biodiesel as a function of temperature, predicted through methodology proposed by Ceriani et al. (2007). As it is possible to observe, the methodology was very feasible, presenting an ARD between experimental and estimated values of $6.10 \%$, with a maximum of $14.58 \%$ and a minimum of $0.31 \%$. A high $\mathrm{R}^{2}$-value $(0.9999)$ confirmed the good quality of the predictive methodology.

The approach suggested by Rodenbush et al. (1999) was tested and the parameters obtained by correlating density with viscosity are given in Table 4 . The high values of correlation coefficients $\left(\mathrm{R}^{2}\right)$ and the low values of the parameter standard deviations indicate the good fitting quality. This is further confirmed by ARD values obtained on the basis of the viscosities calculated using Eq. 6: 1.30\% for microalgae oil and $0.42 \%$ for biodiesel. An important advantage of the model described in Eq. 6 is to allow calculatation of the liquid viscosity through a mathematical model that depends only on density, a property that can easily measured.

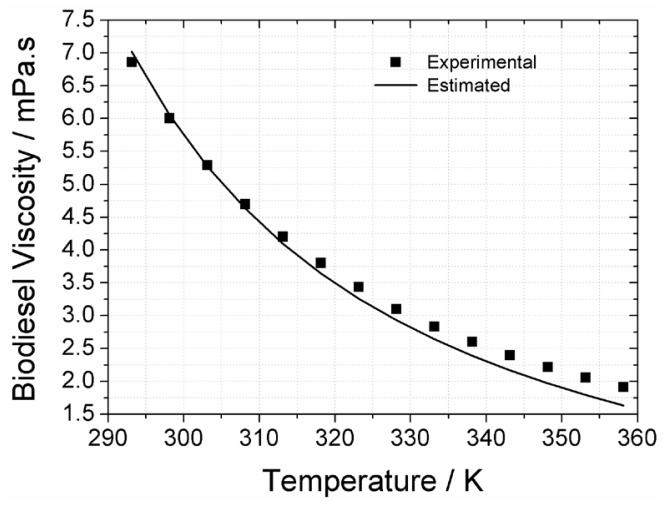

Figure 5. Experimental and estimated microalgae ethylic biodiesel viscosity. 
Table 4. Correlation parameters for Eq 6.

\begin{tabular}{lcccccc}
\hline & $\mathbf{D}$ & SD $^{\mathbf{1}}$ & $\mathbf{E}$ & SD $^{\mathbf{1}}$ & $\mathbf{R}^{\mathbf{2}}$ & $\begin{array}{c}\text { Temperature } \\
\text { Range (K) }\end{array}$ \\
\hline Microalgae Oil & 0.94248 & $3.4 \cdot 10^{-4}$ & -0.2315 & 0.0016 & 0.99940 & $293.15-358.15$ \\
Ethylic Biodiesel & 0.93059 & $3.3 \cdot 10^{-4}$ & -0.15698 & $6.4 \cdot 10^{-4}$ & 0.99978 & $293.15-358.15$ \\
\hline
\end{tabular}

${ }^{1}$ Standard deviation.

\section{Microalgae Ethylic Biodiesel Flash Point}

As indicated in the methodology, the experimental measurements were based on the international norm ASTM D 6450. The results obtained presented an average flash point of $457.05 \mathrm{~K}\left(183.90{ }^{\circ} \mathrm{C}\right)$, with a standard deviation of $0.5 \mathrm{~K}$, for microalgae ethylic biodiesel. This value is in accordance with ASTM D 6450 that establishes a minimum value of $403.15 \mathrm{~K}$ $\left(130^{\circ} \mathrm{C}\right)$.

Results reported in the literature indicate an average flash point of $418.15 \mathrm{~K}$ for used (frying) soybean oil ethylic biodiesel (Uthman and Abdulkareem, 2014), $421.8 \mathrm{~K}$ for palm oil ethylic biodiesel (Carareto et al., 2012), 433.15 for corn oil ethylic biodiesel (Rashid et al., 2012) and $438.15 \mathrm{~K}$ for fresh soybean oil ethylic biodiesel (Martínez et al., 2014). These values are slightly lower than the microalgae-derived ethylic biodiesel studied in this paper, indicating that microalgae biofuel exhibits a higher security during storage and transportation than other biodiesels, since a high value of flash point diminish fire risk.

Flash point values can also be related to the residual alcohol contained in biodiesel and, as a consequence, can be a parameter indicative of its quality. Boog et al. (2011) demonstrated that the presence of residual alcohol in the final biodiesel reduces the flash point, since alcohol volatility is higher than ester volatilities and this reduction is proportional to the ethanol content. Thus, the high value of flash point for microalgae biodiesel indicates that a low amount of residual alcohol is present in the biodiesel, confirming the good quality of the biofuel.

\section{Microalgae Ethylic Biodiesel Cold Flow Properties and Heat Capacity}

The heating and cooling curves from the DSC analysis are represented in Figure 6. It is important to note from Table 1 that the majority of the esters of biodiesel are unsaturated (ethyl oleate), which gives a lower melting temperature compared with other biodiesels rich in saturated fatty acids such as babassu and palm kern oils (Silva et al., 2011; Knothe and Dunn, 2009), which are rich in saturated esters such as ethyl laurate, palmitate and stearate. However, when compared with biodiesel with high unsaturated esters (soybean and corn biodiesel), the melting temperature of microalgae ethylic biodiesel was lower. Once more, this characteristic can be attributed to the high

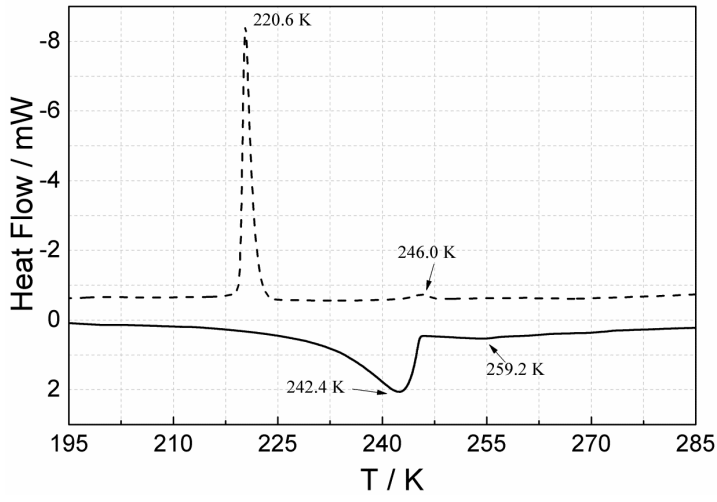

Figure 6. DSC response for the biodiesel with a rate of $2 \mathrm{~K} \cdot \mathrm{min}^{-1}$. Dotted line - cooling curve and solid line - heating curve.

amount of unsaturated esters in microalgae biodiesel that presents more than $92 \%$ unsaturated against an average around $85 \%$ in case of soybean biodiesel.

The biodiesel is a complex mixture of ethyl esters which is responsible for the melt and crystallization profile showed in Figure 6, comprising a wide range of temperature rather than an unique peak, as expected for pure substances. There are two prominent peaks in the DSC cooling curve, at 246.0 and at $220.6 \mathrm{~K}$, as well as two peaks in the DSC heating curve at 242.4 and 259.2 $\mathrm{K}$. The higher enthalpy value peak in the DSC cooling and heating curves cannot be directly associated with the crystallization/melting of the major constituent of microalgae biodiesel (ethyl oleate) which has a melting temperature of $255.12 \mathrm{~K}$ (Costa et al., 2012). So, from the results we can suppose the prevalence of interactions between the biodiesel components in the solid phase, such as eutectic and peritectic mixtures that are very common in such systems (Costa et al., 2011).

Due to the first peak in the cooling curve for all replicates, it is possible to affirm that biodiesel begins its crystallization around an average temperature of $246.0 \mathrm{~K}$. This means that this temperature can be associated with the biodiesel CP. In the case of the heating curve, the second peak, around $259.2 \mathrm{~K}$, can be considered the MP of biodiesel, the temperature at which complete melting can be observed.

The measured specific heat capacities of biodiesel in the temperature range of 270 to $370 \mathrm{~K}$ are shown in Figure $7 \mathrm{a}$. The heat capacity values were fitted using a linear equation (Eq. 10) with coefficient of determination $\left(\mathrm{R}^{2}\right)$ equal to 0.9967 and standard deviations for the model parameters of 0.009 (independent parameter) 

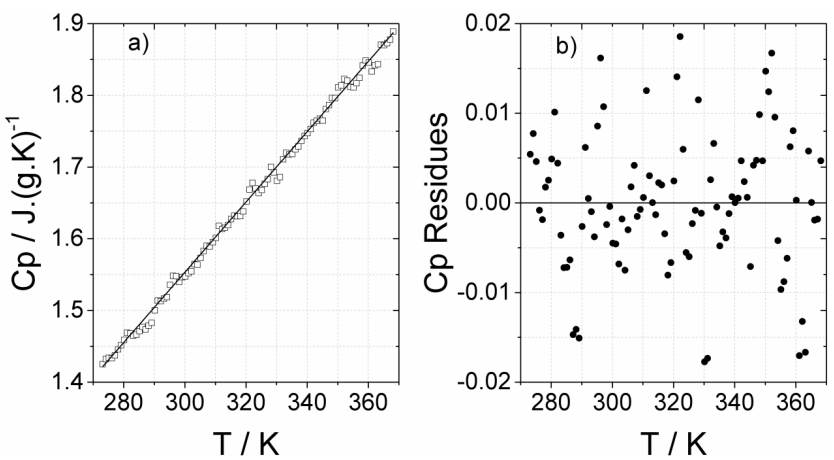

Figure 7. Specific heat capacity for the microalgae biodiesel as a function of temperature using Stepscan DSC method.

and $2.864 \cdot 10^{-5}$ (dependent parameter). The low value of the ARD $(0.38 \%)$ between the experimental and fitted values shows the good accuracy of the linear model. Figure $7 \mathrm{~b}$ presents the residues generated by the $\mathrm{Cp}$ equation (Eq. 10). The randomness of the residues confirms the model reliability.

$$
C p /\left(J \cdot K^{-1} \cdot g^{-1}\right)=0.082+0.0049 \cdot T /(K)
$$

\section{Microalgae Ethylic Biodiesel Cetane Number (CN)}

Table 5 shows the $\mathrm{CN}$ of each pure FAEE present in microalgae biodiesel. Thus, in accordance with Eq. 9, the $\mathrm{CN}$ of microalgae ethylic biodiesel can be estimated to be 51.32 .

The minimum biodiesel $\mathrm{CN}$ is 51 in Europe, 47 in USA and 45 in Brazil. Similarly, in case of fossil diesel, the minimum $\mathrm{CN}$ required in the European Union (EN 590) and USA (ASTM D 975) is 51 and 40, respectively. On the other hand a biodiesel $\mathrm{CN}$ lower than 65 is desirable (Angelovič et al., 2014). Taking these specifications into account, the microalgae ethylic biodiesel reaches all $\mathrm{CN}$ requirements, an additional indication of the viability of this biofuel as an alternative to biodiesel from food vegetable oils.

In general, biodiesel $\mathrm{CN}$ is influenced mainly by the saturation degree and carbon chain size. High saturation and larger carbon chain size increase the $\mathrm{CN}$ while unsaturations decrease the value of this

Table 5. Predict $\mathrm{CN}$ for each FAEE in microalgae biodiesel.

\begin{tabular}{lcc}
\hline \multicolumn{1}{c}{$\begin{array}{c}\text { Biodiesel } \\
\text { FAEE }\end{array}$} & $\begin{array}{c}\text { Composition } \\
(\mathbf{w t} \%)\end{array}$ & $\mathbf{C N}_{\mathbf{i}}$ \\
\hline C 18:0 (Palmitate) & 4.79 & 71.94 \\
C 18:1 (Palmitoleate) & 0.23 & 50.95 \\
C 20:0 (Stearate) & 1.72 & 81.97 \\
C 20:1 (Oleate) & 62.17 & 56.44 \\
C 20:2 (Linoleate) & 22.33 & 46.08 \\
C 20:3 (Linolenate) & 6.66 & 37.24 \\
C 22:0 (Arachidate) & 0.55 & 97.21 \\
C 22:1 (Gadoleate) & 1.55 & 64.76 \\
\hline
\end{tabular}

property (Tong et al., 2011). Thus, as expected, the $\mathrm{CN}$ of microalgae ethylic biodiesel is lower than biodiesels rich in saturated components such as palm biodiesel (CN in a range of 58.3 to 70.0), and similar to unsaturated ones, as such soybean $(\mathrm{CN}$ in a range of 45.0 to 60.0$)$ and sunflower ( $\mathrm{CN}$ in a range of 46.6 to 61.2) biodiesels (Tong et al., 2011).

\section{Summary of Results}

To summarize the results obtained for microalgae oil and its ethylic biodiesel, Table 6 presents the values of the main properties studied in this work.

Table 6. Summary of main properties of microalgae oil and its ethylic biodiesel.

\begin{tabular}{|c|c|c|c|}
\hline & Oil & Biodiesel & $\begin{array}{c}\text { Fossil } \\
\text { Diesel }^{\mathrm{a}}\end{array}$ \\
\hline$\overline{\text { Water content }(\% \mathrm{wt})}$ & 0.086 & 0.018 & - \\
\hline Acidity value (mg KOH.g $\left.\mathrm{g}^{-1}\right)$ & 0.193 & 0.224 & Max 0.5 \\
\hline Density $\left(\mathrm{g} \mathrm{cm}^{-3}\right)$ at $273.15 \mathrm{~K}$ & 0.915 & 0.874 & 0.820 \\
\hline Viscosity $\left(\mathrm{mm}^{2} . \mathrm{s}^{-1}\right)$ at $313.15 \mathrm{~K}$ & 32.86 & 4.88 & 3.20 \\
\hline Flash point $(\mathrm{K})$ & - & 457.05 & 338.15 \\
\hline Cloud point $(\mathrm{K})$ & - & 246.00 & - \\
\hline Melting point $(\mathrm{K})$ & - & 259.20 & - \\
\hline Cetane number & - & 51.32 & - \\
\hline
\end{tabular}

${ }^{\mathrm{a}}$ Uthman and Abdulkareem (2014).

\section{CONCLUSION}

As demonstrated in this paper, microalgae ethylic biodiesel has properties similar to other common biodiesels derived from vegetable oils. Especially in the case of acidity value, water content, flash and pour points, these properties presented values better than other traditional biodiesels. Thus, the present work shows that microalgae lipids are a feasible alternative raw material for biofuel production.

\section{ACKNOWLEDGEMENTS}

The authors thanks FAPESP (2012/08792-0), $\mathrm{CNPq}$ and CAPES for the supporting

\section{REFERENCES}

Alonso, J.F.S.J., Sastre, J.A.L., Romero-Ávila, C., Romero-Ávila, E.L., and Iglesias, C.I., Using mixtures of diesel and sunflower oil as fuel for heating purposes in Castilla y León, Energy, 30 573-582 (2005).

Angelovič, M., Tkáč, Z., and Jablonický, J., Determination Model for Cetane Number of Biodiesel at Different Fatty Acid Composition: a Review. Scientific Papers Animal Science and Biotechnologies, 47(1), 365-371 (2014). 
Antoniosi Filho, N. R., Mendes, O. L., and Lanças, F. M., Computer prediction of triacylglycerol composition of vegetable oils by HRGC. Chromatographia, 40(9-10), 557-562 (1995).

Baroutian, S., Aroura, M.K., Raman,A.A.A., Sulaiman, N.M.N., Densities of Ethyl Esters Produced from Different Vegetable Oils. J. Chem. Eng. Data, 53, 2222-2225 (2008).

Basso, R.C., Meirelles, A.J.A., Batista, E.A.C., Biodiesel Produced by Ethanolysis: Melting Profile, Densities and Viscosities. Energ. Fuel., 27, 5907-5914 (2013a).

Basso, R.C., Meirelles, A.J.A., Batista, E.A.C., Densities and Viscosities of Fatty Acid Ethyl Esters and Biodiesels Produced by Ethanolysis from Palm, Canola, and Soybean Oils: Experimental Data and Calculation Methodologies. Ind. Eng. Chem. Res., 52, 2985-2994 (2013b)

Batista, F.R.M., Follegatti-Romero, L.A., Bessa, L.C.B.A., Meirelles, A.J.A., Computational simulation applied to the investigation of industrial plants for bioethanol distillation. Comput. Chem. Eng., 46, 1-16 (2012).

Boog, J.H.F., Silveira, E.L.C., de Caland, L.B., Tubino, M., Determining the residual alcohol in biodiesel through its flash point. Fuel, 90, 905-907 (2011).

Brunschwing, C., Moussavou, W., Blin, J., Use of bioethanol for biodiesel production. Prog. Energ. Combust., 38, 283-301 (2012).

Carareto, N.D.D., Kimura, C.Y.C.S., Oliveira, E.C., Costa, M.C., Meirelles, A.J.A., Flash points of mixtures containing ethyl esters or ethylic biodiesel and ethanol. Fuel, 96, 319-326 (2012).

Carareto, N.D.D., Costa, M.C., Rolemberg, M.P., Krähenbühl, M.A., Meirelles, A.J.A., The solidliquid phase diagrams of binary mixtures of even saturated fatty alcohols. Fluid Phase Equilibria, 303(2), 191-198 (2011).

Ceriani, R., Gonçalves, C.B., Rabelo, J., Caruso, M.W., Cunha, A.C.C., Cavaleri, F.W., Batista, E.C., Meirelles, A.J.A., A group contribution model for predicting viscosity of fatty compounds. J. Chem. Eng. Data, 52, 965-972 (2007).

Chen, L., Liu, T., Zhang, W., Chen, X., Wang, J., Biodiesel production from algae oil high in free fatty acids by two-step catalytic conversion. Bioresour. Technol., 111, 208-214 (2012).

Chisti, Y., Biodiesel from microalgae beats bioethanol, Trends Biotechnol., 26(3), 126-131 (2008)

Chisti, Y., Fuels from microalgae, Biofuel., 1, 233-235 (2010).

Constantinou, L., Gani, R., New Group Contribution Method for Estimating Properties of Pure Components. AIChE J., 70, 1697-1710 (1994).

Costa, M.C., Boros, L.A.D., Coutinho, J.A.P., Krähenbühl, M.A., Meirelles, A.J.A., LowTemperature Behavior of Biodiesel: Solid Liquid
Phase Diagrams of Binary Mixtures Composed of Fatty Acid Methyl Esters, Energ. Fuel, 25, 32443250 (2011).

Costa, M.C., Boros, L.A.D., Batista, M.L.S., Coutinho, J.A.P., Krähenbühl, M.A., Meirelles, A.J.A., Phase diagrams of mixtures of ethyl palmitate with fatty acid ethyl esters, Fuel, 91, 177-181 (2012).

Costa, M.C., Rolemberg, M.P., Boros, L.A.D., Krahenbuhl, M.A., de Oliveira, M.G., Meirelles, A.J.A., Solid-Liquid Equilibrium of Binary Fatty Acid Mixtures. J. Chem. Eng. Data, 52, 30-36 (2007).

Demirbas, A., Demirbas, M.F., Importance of algae oil as a source of biodiesel. Energ. Convers. Manage., 52, 163-170 (2011).

Endo, Y., Ohta, A., Kido, H., Kuriyama, M., Sakaguchi, Y., Takebayashi, S., Hirai, H., Murakami, C., Wada, S., Determination of Triacylglycerol Composition in Vegetable Oils Using High-performance Liquid Chromatography: A Collaborative Study. J. Oleo Sci., 60, 451-456 (2011).

Esquivel-Hernández, D.A., Ibarra-Garza, I.P., Rodríguez-Rodríguez, J., García-Pérez, J.S., ParraSaldívar, R. Green extraction technologies for highvalue metabolites from algae: a review. Biofuels, Bioproducts and Biorefining, 11(1), 215-231 (2017).

Esteban, B., Riba, J.R., Baquero, G., Rius, A., Puig, R., Temperature dependence of density and viscosity of vegetable oils. Biomass Bioenerg., 42, 164-171 (2012).

Gilbert-López, B., Mendiola, J.A., van den Broek, L.A.M., Herrero, M., Ibáñez, E. Green compressed fluid technologies for downstream processing of Scenedesmus obliquus in a biorefinery approach, Algal Research, 24, 111-121 (2017).

Halvorsen, J.D., Mammel, W.C., Clements, L.D., Density Estimation for Fatty Acid and Vegetable Oils Based on Their Fatty Acid Composition. J. Am. Oil Chem. Soc., 10, 875-880 (1993).

Karpagam, R., Preeti, R., Raj, K.J., Ashokkumar, B., Varalakshmi, P. Fatty acid biosynthesis from a new isolate Meyerella sp. N4: Molecular characterization, nutrient starvation, and fatty acid profiling for lipid enhancement, Energy and Fuels, 29(1), 143-149 (2015)

Kiss, F.E., Jovanovic, M., Boskovic, G.C., Economic and ecological aspects of biodiesel production over homogeneous and heterogeneous catalysts. Fuel Process. Technol., 91, 1316-1320 (2010).

Kizililsoley, M., Helvacioglu, S., Micro-algae growth technology systems [Powerpoint slides]. Retrieved from http://iimsam.org/images/growthtech.pdf(2008)

Knothe, G., Dunn, R.O.A., Comprehensive Evaluation of the Melting Points of Fatty Acids and Esters Determined by Differential Scanning Calorimetry. J. Am. Oil. Chem. Soc., 86, 843-856 (2009). 
Kulkarni, M.G., Dalai, A.K., Bakhshi, N.N., Transesterification of canola oil in mixed methanol/ ethanol system and use of esters as lubricity additive. Bioresource Technol., 98, 2027-2033 (2007).

Kumar, M., Sharma, M. P., Kinetics of Transesterification of Chlorella protothecoides Microalgal Oil to Biodiesel. Waste Biomass Valor, 7, 1123-1130 (2016).

Li, Y.Q., Mu, J.X., Chen, D., Xu, H., Han, F.X., Enhanced lipid accumulation and biodiesel production by oleaginous Chlorella protothecoides under a structured heterotrophic iron (II) induction strategy. World Journal of Microbiology and Biotechnology, 31, 773-783 (2015)

Lôbo, L.P., Ferreira, S.L.C., Cruz, R.S., Biodiesel: quality parameters and analytical methods. Quím. Nova, 32, 1596-1608 (2009).

Lupatini, A.L., Colla, L.M., Canan, C., Colla, E. Potential application of microalga Spirulina platensis as a protein source, Journal of the Science of Food and Agriculture, 97(3), 724-732 (2017).

Mallick, N., Bagchi, S.K., Koley, S., Singh, A.K. Progress and challenges in microalgal biodiesel production, Frontiers in Microbiology, 7, 1-11 (2016).

Martínez, S.L., Romero, R., Natividad, R., González, J., Optimization of biodiesel production from sunflower oil by transesterification using $\mathrm{Na} 2 \mathrm{O} / \mathrm{NaX}$ and methanol. Catal. Today, 220, 12-20 (2014).

Mata, T.M., Martins, A.A., Caetano, N.S., Microalgae for biodiesel production and other applications: a review. Renew. Sustain. Energy Rev., 14, 217-232 (2010)

Melero, J.A., Bautista, L.F., Morales, G., Iglesias, J., Sánchez-Vázquez, R., Biodiesel production from crude palm oil using sulfonic acid-modified mesostructured catalysts, Chem. Eng. J., 161, 323331 (2000).

Moazami, N., Ranjbar, R., Ashori, A., Tangestani, M., Nejad, A.S., Biomass and lipid productivities of marine microalgae isolated from the Persian Gulf and the Qeshm Island. Biomass Bioenerg., 35 1935-1939 (2011).

Naik, S.N., Goud, V.V., Rout, P.K., Dalai, A.K., Production of first and second generation biofuels: A comprehensive review. Renew. Sust. Energ. Rev., 14, 578-597 (2010).

Nwafor, O.M.I., The effect of elevated fuel inlet temperature on performance of diesel engine running on neat vegetable oil at constant speed conditions. Renew Energ., 28. 171-181 (2013).

Radakovits, R., Jinkerson, R.E., Darzins, A., Posewitz, M.C., Genetic engineering of algae for enhanced biofuel production. Eukaryot. Cell, 9, 486-501 (2010).

Rashid, U., Ibrahim, M., Ali, S., Adil, M., Hina, S., Bukhari, I.H., Yunus, R., Comparative study of the methanolysis and ethanolysis of maize oils using alkaline catalysts. Grasas y Aceites, 63, 35-43 (2012).

Refaat, A.A., Correlation between the chemical structure of biodiesel and its physical properties. Int. J. Environ. Sci. Te., 6, 677-694 (2009).

Rocha, E.G.A., Follegatti-Romero, L.A., Duvoisin Jr., S., Aznar, M., Liquid-liquid equilibria for ternary systems containing ethylic palm oil biodiesel + ethanol + glycerol/water: Experimental data at 298.15 and $323.15 \mathrm{~K}$ and thermodynamic modeling. Fuel, 128, 356-365 (2014).

Rodenbush, C.M., Hsieh, F.H., Viswanath, D.S., Density and viscosity of vegetable oils. J. Am. Oil Chem. Soc., 76, 1415-1419 (1999).

Silva, C.C.C.M., Ribeiro, N.F.P., Souza, M.M.V.M., Aranda, D.A.G., Biodiesel production from soybean oil and methanol using hydrotalcites as catalyst, Fuel Process. Technol., 91, 205-210 (2010).

Silva, M.C.D., da Silva, L.M., Santos, N.A., Conceição, M.M., Souza, A.G., dos Santos, A.O., Study of ethylic Babassu biodiesel properties at low temperatures, J. Therm. Anal. Calorim., 106, 363-367 (2011).

Singh, A., Nigam, P.S., Murphy, J.D., Mechanism and challenges in commercialization of algal biofuels. Bioresource Technol., 102, 26-34 (2011).

Tong, M., Hu, C., Jiang, K., Li, Y., Cetane Number Prediction of Biodiesel from the Composition of the Fatty Acid Methyl Esters. J. Am. Oil Chem. Soc., 88, 415-423 (2011).

Uthman, H., Abdulkareem, A.S., The Production and Characterization of Ethyl Ester (Biodiesel) from Waste Vegetable Oil as Alternative to Petro Diesel. Energ. Source Part A, 36, 2135-2141 (2014).

Vyas, A.P., Verma, J.L., Subrahmanyam, N., A review on FAME production processes. Fuel, 89, 1-9 (2010).

\section{APPENDIX A}

Table A.1. Experimental data of Density and Viscosity of microalgae oil and its ethylic biodiesel.

\begin{tabular}{ccccc}
\hline \multirow{2}{*}{$\begin{array}{c}\text { Temperature } \\
(\mathbf{K})\end{array}$} & \multicolumn{2}{c}{ Density $\left(\mathbf{g} \cdot \mathbf{c m}^{-\mathbf{3}}\right)$} & \multicolumn{2}{c}{ Viscosity } \\
\cline { 2 - 5 }$(\mathbf{m P a} \cdot \mathbf{s})$ \\
\hline 293.15 & 0.91560 & 0.87430 & 65.08193 & 6.85308 \\
298.15 & 0.91211 & 0.87065 & 51.94662 & 6.00147 \\
303.15 & 0.90866 & 0.86700 & 42.18426 & 5.28794 \\
308.15 & 0.90520 & 0.86334 & 35.17765 & 4.69467 \\
313.15 & 0.90176 & 0.85971 & 29.64448 & 4.19965 \\
318.15 & 0.89832 & 0.85607 & 24.90216 & 3.80059 \\
323.15 & 0.89488 & 0.85242 & 21.59191 & 3.43251 \\
328.15 & 0.89146 & 0.84880 & 18.63727 & 3.10011 \\
333.15 & 0.88804 & 0.84516 & 16.18822 & 2.83225 \\
338.15 & 0.88462 & 0.84152 & 14.27302 & 2.59896 \\
343.15 & 0.88121 & 0.83788 & 12.57466 & 2.39468 \\
348.15 & 0.87780 & 0.83425 & 11.22698 & 2.21567 \\
353.15 & 0.87440 & 0.83061 & 10.03168 & 2.05560 \\
358.15 & 0.87101 & 0.82697 & 9.00910 & 1.91258 \\
\hline
\end{tabular}

